\title{
Identification of Scopulariopsis Species by Partial 28S rRNA Gene Sequence Analysis
}

\author{
TOMASZ JAGIELSKI ${ }^{1 *}$, KINGA KOSIM ${ }^{1}$, MAGDALENA SKÓRA², ANNA BARBARA MACURA² \\ and JACEK BIELECKI ${ }^{1}$
}

\begin{abstract}
${ }^{1}$ Department of Applied Microbiology, Institute of Microbiology, Faculty of Biology, University of Warsaw, Warsaw ${ }^{2}$ Department of Mycology, Chair of Microbiology, Collegium Medicum, Jagiellonian University, Cracow
\end{abstract}

Submitted 2 April 2013, revised 9 July 2013, accepted 29 July 2013

\author{
Abstract
}

\begin{abstract}
The genus Scopulariopsis contains over 30 species of mitosporic moulds, which although usually saprophytic may also act as opportunistic pathogens in humans. They have mainly been associated with onychomycosis, and only sporadically reported as a cause of deep tissue infections or systemic disease. Identification of Scopulariopsis species still largely relies on phenotype-based methods. There is a need for a molecular diagnostic approach, that would allow to reliably discriminate between different Scopulariopsis species. The aim of this study was to apply sequence analysis of partial $28 \mathrm{~S}$ rRNA gene for species identification of Scopulariopsis clinical isolates. Although the method employed did reveal some genetic polymorphism among Scopulariopsis isolates tested, it was not enough for species delineation. For this to be achieved, other genetic loci, within and beyond the rDNA operon, need to be investigated.
\end{abstract}

Ke y word s: Scopulariopsis sp., molecular diagnostics, mycosis, sequence analysis, species identification

The genus Scopulariopsis accommodates more than 30 species of mitosporic moulds, whose natural habitat is the soil, where they live as saprophytes and are involved in the decay of organic matter. However, some members of the Scopulariopsis genus may cause opportunistic infections in humans. Eight species (S. acremonium, S. asperula, S. flava, S. fusca, S. koningii, S. brevicaulis, S. brumptii, and S. candida) have been reported as causing human diseases. Superficial skin affections, and onychomycosis in particular, are the most predominant clinical manifestations (de Hoog et al., 2000). Much rarer are subcutaneous, deep tissue and disseminated infections, most of which occur in immunocompromised individuals and are associated with high mortality (Isidro et al., 2006; Beltrame et al., 2009; Salmon et al., 2010). Treatment of Scopulariopsis infections is difficult and usually empirically-based, one reason for this being resistance of Scopulariopsis spp. to a broad spectrum of antifungal agents (Cuenca-Estrella et al., 2003; Skóra and Macura, 2011).

At present, identification of Scopulariopsis species largely relies on the phenotype-based methods, employing both morphological and biochemical criteria. These methods however often produce misleading results. They are also laborious and time consuming, as the fungus has to be obtained in pure culture. Therefore, the use of molecular diagnostic methods is desired, since they provide rapid, unambiguous and highly specific identification of fungal pathogens. However, there are very little data on the molecular diagnostics of pathogenic Scopulariopsis spp. in the literature. No information about molecular methods allowing interand intra-species differentiation exists.

The purpose of this study was to apply sequence analysis of a fragment of the $28 \mathrm{~S}$ rRNA gene for the species-level identification of Scopulariopsis clinical isolates.

A collection of 44 Scopulariopsis sp. isolates was recruited. Within this number, there were 40 clinical isolates of Scopulariopsis sp. and 4 reference strains representing S. brevicaulis (CBS 112377, CBS 119549, CBS 147.41, CBS 398.54). All clinical isolates (each isolate represented a single patient) were recovered over a 6-year period (2006-2012) from patient skin and nail samples in the Department of Mycology, Chair of Microbiology, Collegium Medicum, Jagiellonian University. The isolates were cultured on potato dextrose agar (PDA; Difco) slants and preliminary species identification was accomplished by conventional morphological analysis including macroscopic and microscopic characteristics (de Hoog et al., 2000; Larone, 2002).

* Corresponding author: T. Jagielski, Department of Applied Microbiology, Institute of Microbiology, Faculty of Biology, University of Warsaw, I. Miecznikowa 1, 02-096 Warsaw; phone: +48 225541 311; fax: +48 225541 402; e-mail: t.jagielski@biol.uw.edu.pl 
The fungal DNA was extracted using the Fungi\&Plant DNA Isolation Kit (EURx, Poland), after the mycelium had been ground to a fine powder in liquid nitrogen. The DNA concentration was measured with the NanoDrop ${ }^{\circledR}$ N-1000 Spectrophotometer (NanoDrop Technologies, USA). Molecular species identification was performed using a PCR-sequencing assay, as originally described by Monod et al. (2006), with some modifications. Briefly, a part of the 28S rDNA was amplified by PCR with universal primers designated LSU1 (5'-GATAGCGMACAAGTAGAGTG-3') and LSU2 (5'-GTCCGTGTTTCAAGACGGG-3'). The reaction mixtures were prepared by using the TopTaq Master Mix kit (QIAGEN, Germany) in a total volume of $25 \mu$, containing $2 \times$ TopTaq Master Mix (final conc. $1 \times), 0.4 \mu \mathrm{M}$ each primer, and $1 \mu \mathrm{l}$ (ca. 10-20 ng) of template DNA. The thermal cycling profile was $94^{\circ} \mathrm{C}$ for $1 \mathrm{~min}, 30 \mathrm{cycles}$ at $94^{\circ} \mathrm{C}$ for $30 \mathrm{sec}$., $58^{\circ} \mathrm{C}$ for $30 \mathrm{sec}$, and $72^{\circ} \mathrm{C}$ for $30 \mathrm{sec}$., and a final step at $72^{\circ} \mathrm{C}$ for $10 \mathrm{~min}$. The PCR products were resolved by electrophoresis using 3\% agarose gels and were photographed under UV light after ethidium bromide staining. For sequencing, the PCR products were purified using the CleanUp kit (A\&A Biotechnology, Poland). Sequencing was performed on both strands with the primers described above by means of the BigDye ver. 3.1 Terminator Kit (Applied Biosystems) and capillary electrophoresis system ABI 3130xl Genetic Analyzer (Applied Biosystems; Genomed, Warsaw, Poland). Forward and reverse sequences were assembled and edited with ChromasPro ver. 1.7.1 (Technelysium, Australia) and the resulting consensus sequences were searched against the GenBank database of the National Center for Biotechnology Information (NCBI) using the BLASTN algorithm

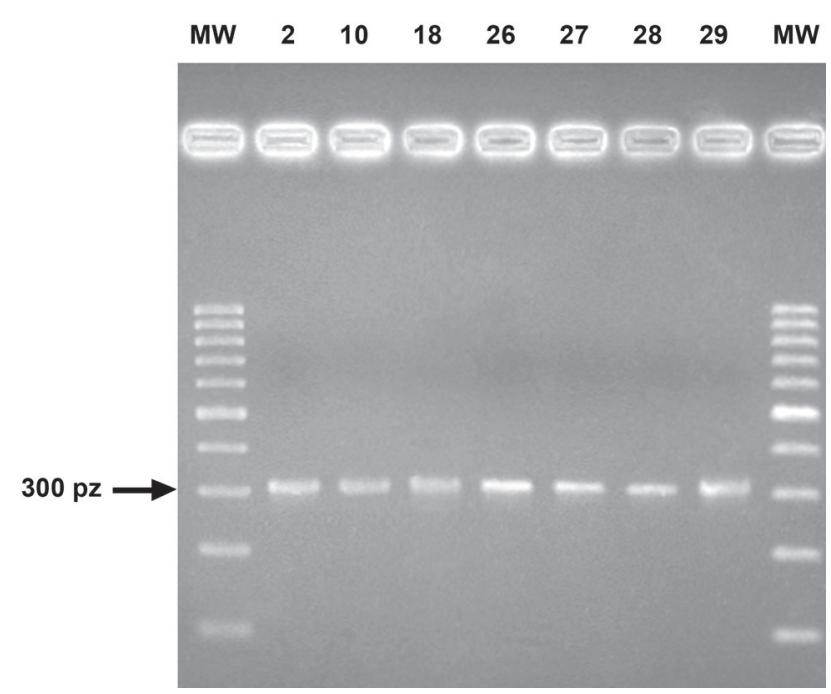

Fig. 1. Results of PCR amplification of a partial 28S rRNA gene for seven selected Scopulariopsis strains. MW, molecular weight marker (DirectLoad ${ }^{\mathrm{TM}}$ PCR 100-bp Low Ladder, Sigma). Numbers above the gel lines refer to the strain numbers.
A

GATAGCGCACAAGTAGAGTGATCGAAAGAT GAAAAGCACT TTGAAAAGAG GATAGCGCACAAGTAGAGTGATCGAAAGAT GAAAAGCACT ITGAAAAGAG **************************************************

AGTTAAAAAGCACGT GAAAT TGTTAAAAGGGAAGCGCTTGCGACCAGACT

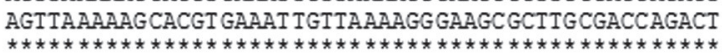

TGCGCCCGICGGATCAACCGICGCT TGCGG CGGCGCACTC CGGCGGGCTC TGCGCCCGTCGGATCAACCGTCGCT TGCGG CGGCGCACTCCGGCGGGCTC

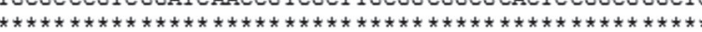

AGGCCAGCAT CAGITCGTCCGGGGGGAGAAAGGCGGCGGGAATGTGGCTC

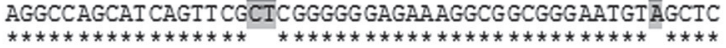

TTCGGAGTGT TATAGCCCGCCGTGT AATACCCTCGGGTGGACTGAGGACC CICGGAGIGT TATAGCCCGCCGIGTAATACCCTCGGGTGGACTGAGGACC

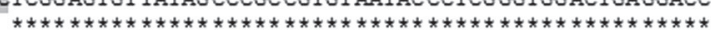

GCGCGTATGCAAGGATGCTGGCGTAATGGT CGTCAGCGACCCGTCTTGAA GCGCGTATGCAAGGATGCTGGCGTAATGGT CGTCAGCGACCCGTCTTGAA

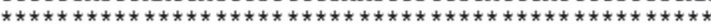

ACACGGAC

ACACGGAC

$\star \star \star \star \star \star \star \star * *$

Fig. 2. A comparison of two types of sequences ("A" and "B") obtained through direct sequencing of a 308-bp fragment of the 28S rRNA gene.

Nucleotide differences between the two sequences are highlighted in grey.

(http://blast.ncbi.nlm.nih.gov/). Sequence identities of $\geq 99 \%$ were used for species identification.

For all the strains tested, a single PCR amplification product of the expected length $(308 \mathrm{bp})$ was obtained (Fig. 1). Two types of sequences of the targeted locus, designated " $\mathrm{A}$ " and " $\mathrm{B}$ " were detected in 43 (including all four reference strains) and one isolates, respectively. These two sequences differed only at four nucleotide positions: 168 ( $\mathrm{T}$ or C), 169 (C or T), 196 (G or A), and 201 (T or C) (Fig. 2). A comparative analysis of the sequences obtained with those deposited in the GenBank database revealed that sequence " $\mathrm{A}$ " was identical (100\% match) with the GenBank sequences derived from 14 strains of S. brevicaulis and 4 strains of Microascus manginii (teleomorph of Scopulariopsis candida). Whereas, sequence "B" was found identical to that of S.fusca (10 strains), S. asperula (one strain), and $M$. manginii (3 strains) from the GanBank database (Table I).

The results from this study did confirm that the analysed strains belong to the Scopulariopsis genus, yet they did not allow to precisely assign the strains to the species level. All but one Scopulariopsis strains tested had a partial $28 \mathrm{~S}$ rDNA sequence identical with that of S. brevicaulis and M. manginii. Given the fact, that all four reference strains of $S$. brevicaulis were within this group, and that M. manginii has not been associated with human infection (in the literature, only one case of an invasive sinonasal infection caused by S. candida, the anamorphic form of M. manginii, was described in a young female non-Hodgkin's lymphoma patient (Kriesel et al., 1994)), it can be assumed that these strains truly represent the $S$. brevicaulis species. As for one strain, whose partial 28S rDNA sequence 
Table I

Comparison of the obtained sequences with the GenBank database

\begin{tabular}{|c|c|c|c|}
\hline Sequence type ${ }^{a}$ & GenBank no. & Strain $^{\mathrm{b}}$ & Sequence homology \\
\hline \multirow[t]{18}{*}{ A $(1-17 ; 19-44)$} & JQ434664.1 & Scopulariopsis brevicaulis CBS 334.35 & \multirow[t]{18}{*}{$100 \%$} \\
\hline & JQ434663.1 & Scopulariopsis brevicaulis CBS 152.22 & \\
\hline & JQ434662.1 & Scopulariopsis brevicaulis CBS 119549 & \\
\hline & JQ434661.1 & Scopulariopsis brevicaulis DTO 145A5 & \\
\hline & JQ434660.1 & Scopulariopsis brevicaulis DTO 145A3 & \\
\hline & JQ434659.1 & Scopulariopsis brevicaulis DTO $141 \mathrm{I} 3$ & \\
\hline & JQ434658.1 & Scopulariopsis brevicaulis DTO 145A4 & \\
\hline & JQ434657.1 & Scopulariopsis brevicaulis LCP 70.3042 & \\
\hline & JQ434656.1 & Scopulariopsis brevicaulis LCP 83.3363 & \\
\hline & JQ434655.1 & Scopulariopsis brevicaulis LCP 00.672 & \\
\hline & JQ434654.1 & Scopulariopsis brevicaulis DTO $148 \mathrm{H} 5$ & \\
\hline & JQ434653.1 & Scopulariopsis brevicaulis DTO 145A2 & \\
\hline & JQ434652.1 & Scopulariopsis brevicaulis DTO 141I8 & \\
\hline & JN938873.1 & Scopulariopsis brevicaulis DAOM 225612 & \\
\hline & JQ434650.1 & Microascus manginii DTO 2B3 & \\
\hline & JQ434649.1 & Microascus manginii DTO 145B3 & \\
\hline & JQ434648.1 & Microascus manginii CBS 399.34 & \\
\hline & JQ434651.1 & Microascus manginii CBS 206.61 & \\
\hline \multirow[t]{14}{*}{ B (18) } & JQ434678.1 & Scopulariopsis fusca CBS 114063 & \multirow[t]{14}{*}{$100 \%$} \\
\hline & JQ434677.1 & Scopulariopsis fusca CBS 289.38 & \\
\hline & JQ434676.1 & Scopulariopsis fusca CBS 334.53 & \\
\hline & JQ434675.1 & Scopulariopsis fusca CBS 401.34 & \\
\hline & JQ434674.1 & Scopulariopsis fusca CBS 668.74 & \\
\hline & JQ434673.1 & Scopulariopsis fusca CBS 872.68 & \\
\hline & JQ434672.1 & Scopulariopsis fusca DTO 145A8 & \\
\hline & JQ434671.1 & Scopulariopsis fusca DTO 145A6 & \\
\hline & JQ434670.1 & Scopulariopsis fusca LCP 65.742 & \\
\hline & JN938872.1 & Scopulariopsis fusca DAOM 216340 & \\
\hline & JQ434668.1 & Microascus manginii MUCL 31465 & \\
\hline & JQ434667.1 & Microascus manginii MUCL 31574 & \\
\hline & JN938874.1 & Microascus manginii DAOM 225614 & \\
\hline & JQ434669.1 & Scopulariopsis asperula CBS 853.68 & \\
\hline
\end{tabular}

a Two types of a partial 28S rDNA sequence, designated "A" and "B", found among the 44 Scopulariopsis strains tested in this study. Numbers in brackets refer to the numbers of the strains analysed;

${ }^{b}$ Strains, whose partial 28S rDNA sequence were deposited to the GenBank database under the accession number given in the preceding column (GenBank no.).

was found identical to that of S. fusca, S. asperula, and M. manginii, its species identity can only be surmised from the frequencies of perfect sequence alignments. Consequently, the strain could be recognized as $S$. fusca, since a sequence match with that species was most common. Both S. fusca and S. asperula have been described, albeit rarely, as the causative pathogens of human onychomycosis (de Hoog et al., 2000).

The results of this study show a highly conserved nature of the large-subunit ribosomal DNA sequence. The high homology of the analysed partial 28S rDNA sequence among different Scopulariopsis species pre- cludes its use as a marker for species differentiation. Identification of fungal strains as representing S. brevicaulis, based solely on the results from the method applied in this study (Monod et al., 2006; Bontems et al., 2009), is erroneous and is caused by an a priori assumption that Scopulariopsis strains found in dermatological material most probably are S. brevicaulis. However, the latter species is indeed the most common Scopulariopsis species observed clinically.

To conclude, to the best of authors' knowledge this is the first report on the molecular identification of Scopulariopsis species from Poland. Sequence analysis of partial 
$28 \mathrm{~S}$ rDNA, as applied in this study, did show some genetic polymorphism among Scopulariopsis strains, but it was not enough, however, for species delineation. For this to be achieved, other genetic loci, not only within the rDNA operon, but also protein-coding genes, such as RPB, TUBB, ATP6, and TEF1 $\alpha$, coding for RNA polymerase, $\beta$-tubulin, ATP synthase, and elongation factor EF-1 $\alpha$, respectively, need to be investigated.

There is still a need for a new, diagnostic approach, that would be able to reliably discriminate between Scopulariopsis species. The present study only opens the field of research in this direction.

\section{Acknowledgments}

The study was financed by the Ministry of Science and Higher Education «Iuventus Plus» grant (Contract No. IP12013023672) and by the National Science Center grant (Contract No. N N401 548140).

\section{Literature}

Beltrame A., L. Sarmati, L. Cudillo, R. Cerretti, A. Picardi, L. Anemona C. Fontana, M. Andreoni and W. Arcese. 2009. A fatal case of invasive fungal sinusitis by Scopulariopsis acremonium in a bone marrow transplant recipient. Int. J. Infect. Dis. 13: 488-492. Bontems O., P.M. Hauser and M. Monod. 2009. Evaluation of a polymerase chain reaction-restriction fragment length polymor- phism assay for dermatophyte and nondermatophyte identification in onychomycosis. Br. J. Dermatol. 161: 791-796.

Cuenca-Estrella M., A. Gomez-Lopez, E. Mellado, M.J. Buitrago, A. Monzón and J.L. Rodriguez-Tudela. 2003. Scopulariopsis brevicaulis, a fungal pathogen resistant to broad-spectrum antifungal agents. Antimicrob. Agents Chemother. 47: 2339-2341.

de Hoog G.S., Guarro, J., Gené, J., and M.J. Figueras. 2000. Atlas of clinical fungi, $2^{\text {nd }}$ ed. Centralbureau voor Schimmelcultures, Utrecht, The Netherlands.

Isidro A.M., V. Amorosa, G.A. Stopyra, H.L. Rutenberg, W.H. Pentz and C.R.J. Bridges. 2006. Fungal prosthetic mitral valve endocarditis caused by Scopulariopsis species: case report and review of the literature. Thorac. Cardiovasc. Surg. 131: 1181-1183.

Kriesel J.D., E.E. Adderson, W.M. Gooch and A.T. Pavia. 1994. Invasive sinonasal disease due to Scopulariopsis candida: case report and review of Scopulariopsosis. Clin. Infect. Dis. 19: 317-319.

Larone D.H. 2002. Medically important fungi: a guide to identification, $4^{\text {th }}$ ed. Washington, D.C.

Monod M., O. Bontems, C. Zaugg, B. Léchenne, M. Fratti and R. Panizzon. 2006. Fast and reliable PCR/sequencing/RFLP assay for identification of fungi in onychomycoses. J. Med. Microbiol. 55: 1211-1216.

Salmon A., A. Debourgogne, M. Vasbien, L. Clément, J. Collomb, F. Plénat, P. Bordigoni and M. Machouart. 2010. Disseminated Scopulariopsis brevicaulis infection in an allogeneic stem cell recipient: case report and review of the literature. Clin. Microbiol. Infect. 16: 508-512.

Skóra M. and A.B. Macura. 2011. In vitro antifungal susceptibility testing of Scopulariopsis brevicaulis strains using agar diffusion method. Wiad. Parazytol. 57: 111-116. 